\title{
The Paper Titled "Employee Engagement Bridging Gap Between Anticipated Success and Actual Success Status
}

\author{
Dipti Kanwar, Dr. Vijeta Soni, Assistant Professor, \\ Dr. Pooja Sharma, Assistant Professor. \\ ${ }^{1}$ JECRC University, Jaipur, Rajasthan, India
}

\begin{abstract}
I. Introduction
WHAT IS EMPLOYEE ENGAGEMENT?

Employee Engagement means entirely different things to different audiences. The concept has been defined in numerous ways all over the Globe based on its understanding. There are a number of even contradictory definitions are available.
\end{abstract}

\section{Employee Engagement defined:}

"Employee Engagement is an important key to organizational success. Since, an engaged employee performs better and helps an organization to gain competitive advantage therefore, it is important to know what activities an organization should do in order to engage their employees."

Kahn (1990) defined engagement as a condition where employees remain psychologically present while occupying and performing an organizational role. He argued that it is different from commitment, job involvement or intrinsic motivation. Since then the term has been defined by a number of researchers. Towers (2007) defined employee engagement as Employees' willingness and ability to contribute to company success. Hewitt (2010) referred to Employee engagement as a sense of belonging to the organization. Institute for Employment studies (IES, 2003) defines employee engagement as a positive attitude held by the employee towards the organization and its values. According to the Corporate Executive Board of US (2004), Employee Engagement is defined as "the extent to which employees commit to something or someone in their organization, how hard they work and how long they stay as a result of that commitment".

Hay Group (2002) termed Employee Engagement as 'a result achieved by stimulating employees' enthusiasm for their work and directing it toward organizational success.

The first published use of the term employee engagement was made by Kahn in 1990. He defined engagement as a condition where employees remain psychologically present while occupying and performing an organizational role. The definition of employee engagement has been given by a number of renowned authors but the researcher's understanding of the concept says that it is simply concerned about an employee's attitude and desire of working in the best possible manner for the organization. The willingness of an employee to go the extra mile to make its customers satisfied and let its organization taste success can be better referred to as employee engagement.

\section{WHY IT MATTERS TO ENGAGE EMPLOYEES?}

Employees are the lifeline of an organization. Employees play a vital role in any organization; they hold significance in achieving company goals. Peter Drucker, the late management guru, after years of research concluded that the most influential and important five letter word in business begins with $\mathrm{P}$, which stands for People, (Kelleher, 2009).

Engagement is a two way process between an employer and an employee. The employer attempts to engage employees who return a level of engagement. Employee engagement is beneficial for an organization as engaged employees may be the difference between surviving and thriving when business needs to either more or less.

Employee engagement is a noteworthy need for businesses. It is greatly important to address employee engagement for the purposes of employee retention and organizational profitability; (Cadence Human Systems study, 2007). The Gallup Organization (2004) found significant links between employee engagement, business growth, profitability and customer loyalty. 
It matters to engage employees, explains the given cases:

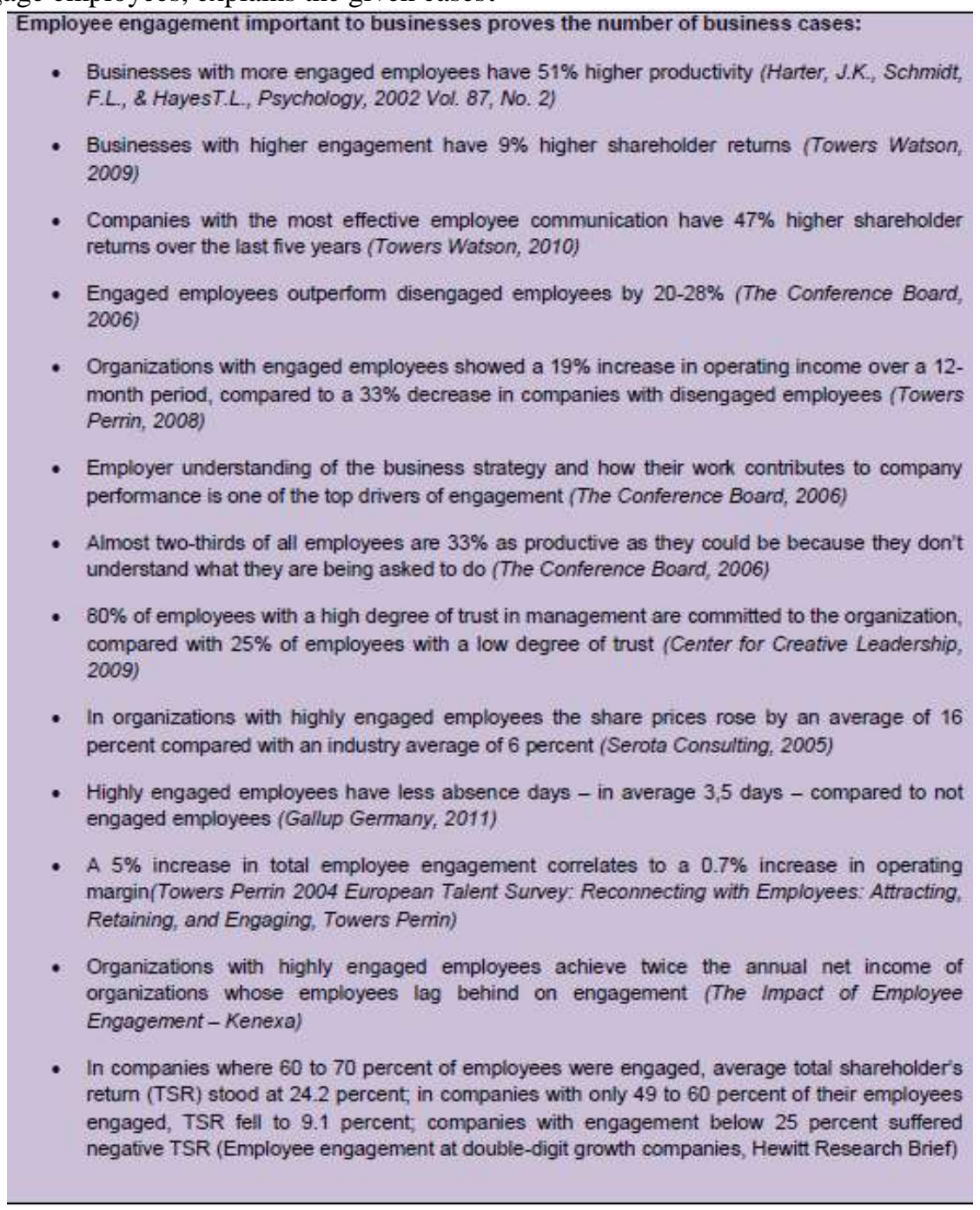

It is very important to have engaged workforce as an engaged employee is emotionally involved in the tasks of his/her company and also helps willingly in achieving company goals. Also an engaged employee help an organization reap benefits such as higher productivity, increased profits, enhanced performance, lower turnover rates, higher levels of customer satisfaction as well as highly satisfied workforce, (Buhler, 2006).

The success of any company in any industry is assessed through competitive advantage. In determining the competitiveness of a company employee engagement plays a critical role, (Ncube and Jerie, 2012). Engaged employees within an organization provide a competitive advantage to organizations, (Joo\& Mclean, 2006). Aon Hewitt (2008-10) revealed that better financial performance, larger talent pools and decrease in employee turnover imply high levels of employee engagement and also distinguish best employers.

\section{What Drives Engagement?}

There are many organizational individual and factors that determine whether employees are engaged or not. If they are engaged, then to what extent they are engaged and if they are disengaged, what could be the reason behind the lack of engagement. Today, employee engagement and loyalty are critical than ever before to an organization's success and to gain competitive advantage. The greatest rewards for an organization are warned by employees. Manpower is the biggest investment for any business. It is required to consider employees one step up from just assets and to engage them. Engagement is basically a long term process which begins with good communication between employees, co-workers and employer to encourage better working environment.

It is the responsibility of an organization to lead engagement among its employees. For the same there are certain key areas like effective management, right people doing right job, open communication channel, career advancement opportunities, training and development as an individual, safety, equal treatment, health, pay and benefits have been found which have great impact on engagement levels. 
The Paper Titled "Employee Engagement Bridging Gap Between Anticipated Success and Actual ..

There are numerous factors that determine levels of employee engagement. A number of drivers' models are available to help understand the concept better. However, a study carried out by Aon Hewitt labels the drivers of employee engagement in better manner in his drivers' model.

Aon Hewitt defines employee engagement as the state of intellectual and emotional involvement that encourages the employees to work in the best manner. Hewitt proposed a model of employee engagement which observes both an employee's state of engagement as well as organizational antecedents.

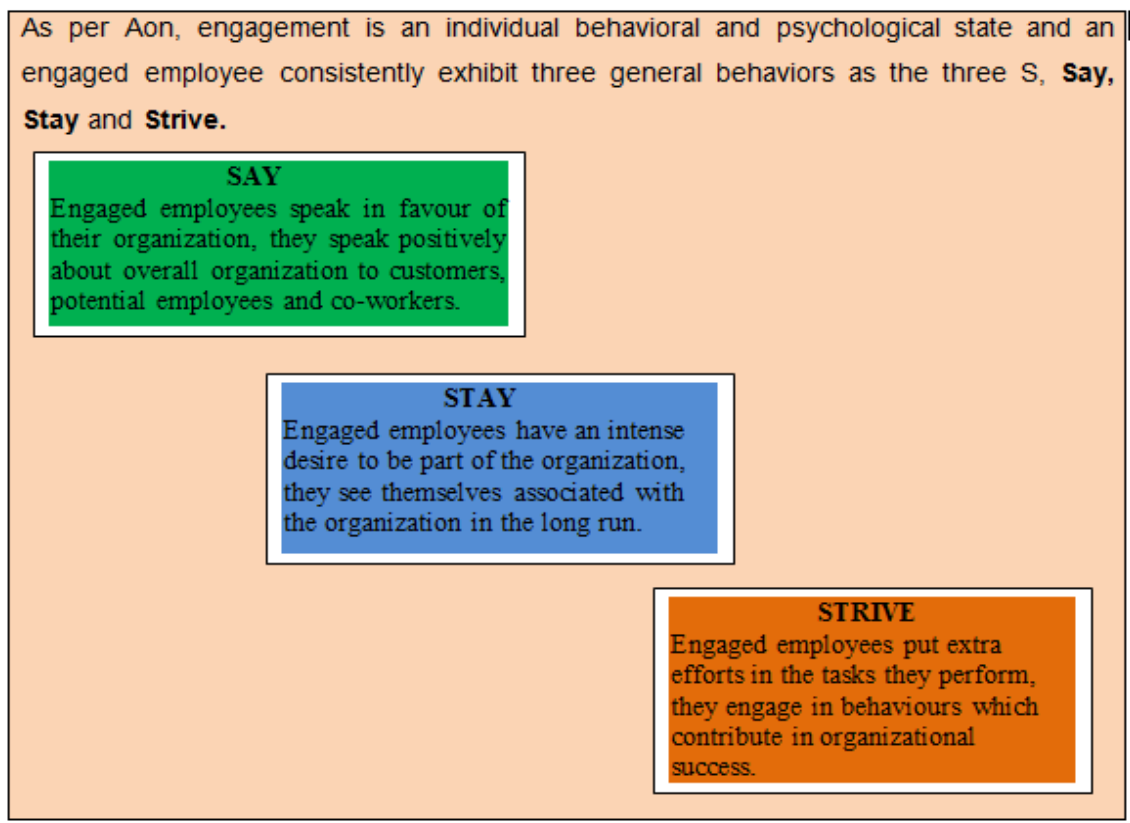

Figure 1: Aon Hewitt's Employee Engagement Model

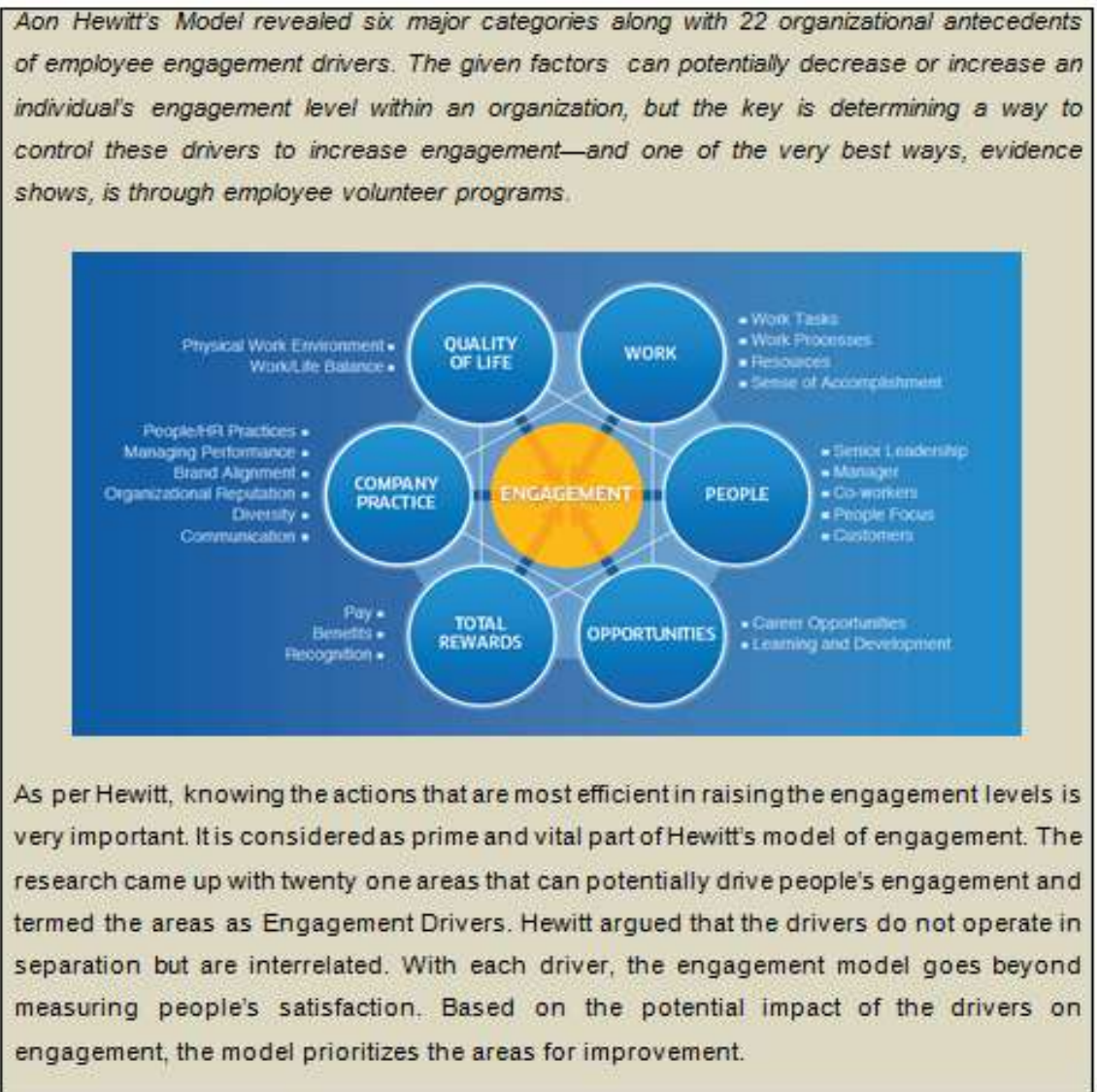

Figure 5.3.1: Figure showing Engagement Drivers as identified by Aon Hewitt 
With the identification of these drivers, an employer can get better understanding of the needs of the workforce and the ways of meeting the needs. Once the needs and specific areas are identified, employer can focus on improvement of those areas so that business results and engagement could be increased. The study describes various dimensions that helps in engaging employees and their employment experiences. It also highlights the changes in current workforce in terms of engagement.

\section{How Employee Engagement benefits?}

Engagement is a two way process between an employer and an employee. The employer attempts to engage employees who return a level of engagement. Employee engagement is beneficial for an organization as engaged employees may be the difference between surviving and thriving when business needs to either more or less. The benefits of employee engaged are being observed by a number of researchers based on practical findings.

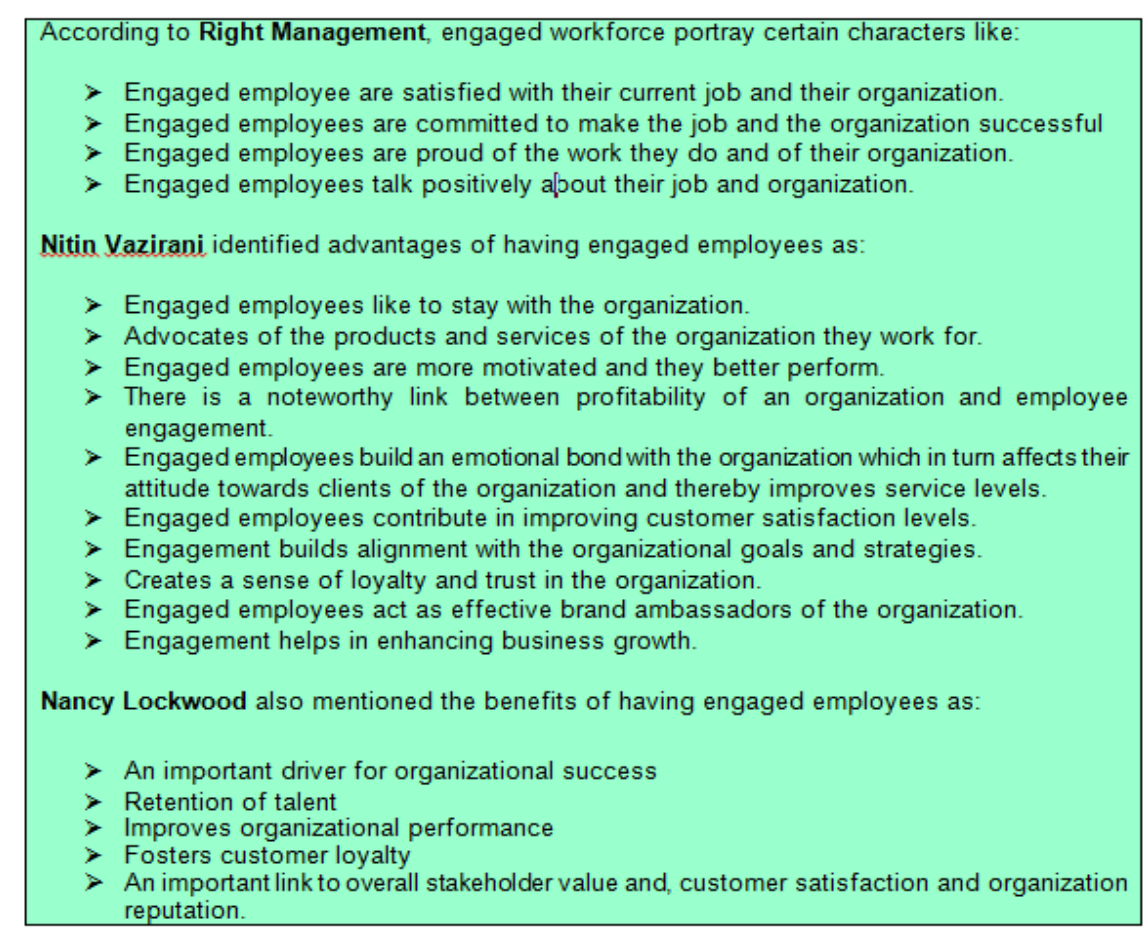

Engaged employees are linked with enhanced performance, greater profits, increased financial gains, increased productivity and ultimately with overall organizational performance.

\section{Want to know who are doing it right?}

Companies which are enjoying success as a result of highly engaged workforce understand that motivating high performance and aligning talent with business strategy requires getting to the heart of what matters to employees.

Google, Facebook, DHL Express, SAP, Southwest Airlines, Philips Companies are nailing employee engagement.

\section{Google}

Google is known for creating an environment for employees to flourish. At Google, employees enjoy free gourmet food and on-site laundry service. The top reason of Google being ranked consistently as a great place to work is its corporate culture.

\section{facebook}

Facebook is also open about its culture. It openly articulates its values through various mediums like posters, employee communications or in meetings. At Facebook, it is ensured that employee values align with the company. 


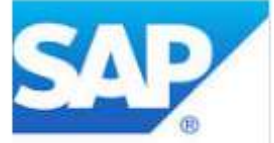

At SAP, culture is to the core of the organization. The best thing about SAP is that employees are very well aware of "why" behind their jobs. They clearly understand their role and they know as to what they're expected to achieve and why it's important to the greater good of the organization.

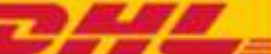

At DHL, employees are thanked in unique way for their efforts and performance whether that's through monetary rewards or through pinning notes of appreciation on the company corkboard. Employees are appreciated for contributions big or small.

\section{Southwest。}

Southwest Airlines is a well-known for outstanding employment branding. It is recognized as being fast, fun and friendly. It is a fun and cool place to work as per the employees associated with it. The main motto is to ensure that the right people are attracted to the organization.

Organizations all over the globe now know and understand the importance of their people/employees and also understand that, "The challenge today is not just retaining talented people, but fully engaging them" (Vance, 2006). A number of studies taking employees as base have been carried out but in recent years employee engagement managed to attract interest.

\section{References}

[1]. Corporate Leadership Council, "Driving Performance and Retention Through Employee Engagement, Research Summary", Corporate Executive Board, $95-98$ (2004).

[2]. Crim Dan and Seijts Gerard, "What Engages Employees the Most or, The Ten C's of Employee Engagement", The workplace, Ivey Business Journal, http://www.iveybusinessjournal.com/topics/the-workplace/what-engages-employees-the-most-or-the-ten-cs-ofemployee-engagement, Accessed: December 2012. (2006)

[3]. Dale Carnegie Training, "What Derives Employee Engagement and Why it Matters", Dale Carnegie Training White Paper, 6-10, (2012).

[4]. David Weiss and Vince Molinaro, “The Leadership Gap: Developing leaders for Competitive Advantage”, 33. (2005).

[5]. De Lacy, Jonnie C, "The development of a three dimensional model of engagement; and an exploration of its relationship with affective leader behaviours", 46-56, (2009).

[6]. "Employee Engagement in the Public Sector", a review of Literature, Scottish Executive Social Research, Available at: http://www.scotland.gov.uk/Resource/Doc/176883/0049990.pdf, Accessed: July 2013, (2007).

[7]. Farai Ncube and Steven Jerie, "Leveraging Employee Engagement for Competitive Advantage in the Hospitality Industry", Scholar link Research Institute Journals, 2, 12-21 (2012)

[8]. Gallup Consulting, "What's your Engagement Ratio", 3-1 (2008).

[9]. Harter J.K., Schmidt, F.L., and Keyes L.M. Corey, "Well Being in the Workplace and Its Relationship to Business Outcomes: A Review of Gallup Studies", 14-16 (2002).

[10]. Hay Group, "Why does Employee Engagement matter to CEO's", 49-50 (2012)

[11]. Hewitt, "Hewitt Point of View: What Makes a Organization a Best Employer?" Hewitt Associates LLC, 39-41(2009).

[12]. Joseph BergHind, (in association with NatCen Social Research), "Measuring, Monitoring And Maintaining Employee Engagement", Employee Engagement Workshop, London, 20-24 (2012)

[13]. Lockwood R Nancy, "Leveraging Employee Engagement for Competitive Advantage: HR's Strategic Role", SHRM (Society for Human Resource Management) research quarterly, 4-8. (2007).

[14]. Macey, W.H., \& Schneider, B. “The Meaning of Employee Engagement, Industrial and Organizational Psychology”, 1 (1): 330 (2008)

[15]. Perrin Towers, “Working Today: Understanding What Derives Employee Engagement”, The Towers Perrin Talent Report, 9, 2, 87 99 (2003)

[16]. Robinson D., Perryman S., Hayday S., “The Drivers of Employee Engagement”, IES (Institute for Employment Studies), Report 408, Available at: http://www.employment-studies.co.uk/pubs/summary.php?id=408. Accessed: May 2013.

[17]. The Employee Engagement Report, "Beyond the number: a practical approach for individuals, managers, and executives", Blessing white research, Global engagement report, p 55. (2010)

[18]. Towers Watson, Global Workforce Study, www.towerswatson.com/DownloadMedia.aspx?media=D1E4CAF3-55FB-45B9-9A14B384BF7E9A66. 